\title{
Macronutrients as sources of food energy
}

\author{
Andrew M Prentice* \\ MRC International Nutrition Group, London School of Hygiene and Tropical Medicine, Keppel Street, London, \\ WCIE 7HT, UK and MRC Keneba, The Gambia
}

\begin{abstract}
This background paper considers the extent to which the development of new recommendations for dietary energy requirements needs to account for the macronutrient (fat, carbohydrate, protein and alcohol) profiles of different diets. The issues are discussed from the dual perspectives of avoiding under-nutrition and obesity. It is shown that, in practice, human metabolic processes can adapt to a wide range of fuel supply by altering fuel selection. It is concluded that, at the metabolic level, only diets with the most extreme macronutrient composition would have any consequences by exceeding the natural ability to modify fuel selection. However, diets of different macronutrient composition and energy density can have profound implications for innate appetite regulation and hence overall energy consumption.
\end{abstract}

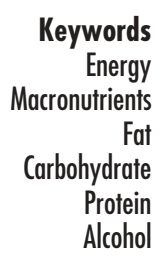

\section{Introduction - macronutrients as sources of food energy}

The four principal classes of macronutrients providing food energy to humans are: carbohydrate, fat, protein and alcohol. Each of these has numerous sub-types with specific attributes in terms of energy delivery and potential health effects. The gross and metabolisable energy contents of the macronutrients in their traditional (natural) forms are well established and there is little need to update the description provided in the 1985 Food and Agriculture Organization/World Health Organization/United Nations University (FAO/WHO/UNU) Report on Energy and Protein Requirements ${ }^{1}$. New issues relating to computation of the energy yield from modern manufactured foods (e.g. non-fat fats such as Olestra) are reviewed elsewhere for this Consultation ${ }^{2}$.

In preparing this background paper it has been assumed that the primary focus is on the energy needs of populations rather than on the other health aspects of diet composition. The latter have been dealt with in recent FAO consultations on fats and oils ${ }^{3}$ and on carbohydrates ${ }^{4}$, and it was recommended that the views of these consultations were highlighted in the final report without being re-reviewed by the current consultative group. Reference to these will be made below but there will be no attempt to challenge the recommendations, which appear generally sound.

It will further be assumed that alcohol should not be recommended as a source of food energy, and that energy derived from protein is obtained as an 'accidental' byproduct of protein degradation. Protein recommendations will be set according to amino acid requirements and there is no need to consider protein's contribution to dietary energy in setting these figures. Therefore, the main discussion will centre on carbohydrates and fats as energy substrates.

\section{New challenges since 1985}

The main tenor of the FAO/WHO/UNU 1985 report was towards ensuring a sufficient intake of dietary energy ${ }^{1}$. The report presented a radically new system for calculating requirements (the basal metabolic rate $(\mathrm{BMR}) \times$ physical activity level $(\mathrm{PAL})$ system) which has since been widely validated and universally adopted. While ensuring that minimal requirements are met remains a vital function in much of the world's population, this task has now been broadened by the addition of a new challenge - that of limiting energy intakes in order to control the epidemic of obesity sweeping through both developed and developing nations. Many affluent nations have experienced a trebling in the rates of clinical obesity since the 1985 report was published, and in urban areas of less affluent countries the problem is developing even more rapidly. It is recommended that the forthcoming report should cover the problem of obesity, and much of what is presented below addresses this issue since macronutrient selection may play an important role in modulating energy intake in line with energy needs.

In this respect, it is now appreciated that the 'energy density' of diets is crucial in determining spontaneous energy intake, and it is further recommended that the new 
report discusses energy density and frames its recommendations with this in mind.

\section{Brief summary of the energy-yielding macronutrients}

\section{Alcobol}

For the purposes of this consultation it is assumed that there are no circumstances in which alcohol is recommended as an energy-giving substrate. In some populations alcohol may contribute up to $5 \%$ of energy or more, and in some individuals it may represent a much greater proportion of food energy. There has been considerable debate about whether the energy from alcohol 'counts' towards doing useful biochemical work or whether it is simply dissipated as heat ${ }^{5-7}$. Most of the evidence suggesting that alcohol energy may not count has been derived from indirect inferences concerning weight changes associated with varying alcohol intakes ${ }^{8,9}$. These are unreliable. Objective evidence derived from calorimetric measurements clearly indicates that alcohol energy must be considered in the overall energy balance equation $^{7,10}$.

If it is accepted that the current consultation will not be making any specific recommendation concerning alcohol intakes then the only implication of the above statement is that it must be recognised that many people do in practice consume alcohol and that it does contribute to their energy needs. Thus, calculations about the intake of the other macronutrients must be 'discounted' appropriately to make allowance for de facto consumption of alcohol.

\section{Protein}

Recommendations on protein intakes will be dealt with elsewhere in this consultative process. Protein requirements are not calculated with a view to protein supplying dietary energy. Although there are important interactions between protein requirements and energy supply (especially carbohydrate), these are more critical in the direction of energy modulating protein needs, rather than vice versa. There are, however, two new areas of controversy that have emerged since the 1985 report in respect of the potential impact of protein supply on obesity.

The first is the suggestion that high protein intakes in childhood may be causally associated with the development of obesity ${ }^{11}$. This thesis is based largely on cross-sectional association studies and on extrapolation from some animal studies. Both lines of argument are vulnerable, and there is epidemiological evidence to refute the theory ${ }^{12}$. So far the proponents of the high protein theory have not yet managed to convince the wider scientific community. It is highly likely that this issue will already have been considered within the background papers for the consultation on protein requirements. If this is not the case, then it should be referred to the protein group.
The second new area of controversy is whether high protein intakes are useful in down-regulating appetite and hence maintaining energy balance in sedentary societies. Most of the evidence for this comes from short-term experiments on satiety ${ }^{13}$, or from studies of intentional weight loss using high protein diets ${ }^{14,15}$. The latter are probably irrelevant to the general issue of protein as an energy-yielding macronutrient. Thus, the remaining issue is whether it is possible or prudent to issue any advice about whether levels of protein intake in excess of that needed for the provision of amino acids would be desirable in order to aid weight control. It is recommended that there is so far insufficient evidence to underpin such advice and that it could be detrimental for a number of reasons (including the general co-existence of animal protein with high levels of saturated fat).

\section{Carbobydrate}

An abbreviated summary of FAO/WHO recommendations on carbohydrate intake in relation to energy requirements is listed in Table 1. A notable omission from these recommendations (compared to many country-specific guidelines) is any limitation on sucrose or simple sugars intakes. The consultation stated that, "There is no evidence of a direct involvement of sucrose, other sugars and starch in the etiology of lifestyle-related diseases'. Instead of issuing direct guidance on sugars intake the consultation dealt with the issue by extolling the virtues of complex carbohydrates. The failure to detect any obvious relationships between simple sugars intake and obesity at the population level is counter-intuitive but has been examined in considerable depth ${ }^{16,17}$. However, at the individual level it seems likely that the very large simple sugars intakes observed in some individuals (particularly adolescents and particularly from carbonated beverages) must play a role in excess energy consumption ${ }^{18}$. Simple sugars are also major contributors to the energy density of diets (see below) and the consultation may, therefore, wish to advise on acceptable upper limits of intake in individuals

\section{Fat}

The FAO/WHO recommendations on fat intake are summarised in Table 2 . These recommendations are prudent and the specific considerations of energy balance

Table 1 FAO/WHO recommendations on dietary carbohydrate

- Optimal diet has at least 55\% of total energy from a variety of carbohydrates for all ages except children under the age of 2 years.

- Fat should not be specifically restricted in children under 2 years. - The bulk of carbohydrate-containing foods should be rich in non-starch polysaccharides and with low glycaemic index.

FAO - Food and Agriculture Organization; WHO - World Health Organization.

Source: Joint FAO/WHO Expert Consultation on Carbohydrates in human nutrition ${ }^{4}$. 
Table 2 FAO/WHO recommendations on dietary fat

- Dietary fat should supply at least $15 \%$ of energy for most adults.

- Women of reproductive age should consume at least $20 \%$ of energy from fat.

- Diets of young children should undergo a gradual transition from breast-milk (50-60\% energy from fat) towards the adult recommendations, with care taken to avoid dietary fat intake falling too rapidly or below required levels for growth and development. During weaning and until 2 years a child's diet should contain $30-40 \%$ energy from fat. Adequate intakes of EFAs must be maintained.

- Sedentary individuals should not consume more than $30 \%$ energy from fat.

- Active individuals in energy balance may consume up to $35 \%$ energy from fat.

- Intakes of saturated fat should not exceed $10 \%$ of energy.

- Linoleic acid should provide 4-10\% energy.

- Cholesterol intake restricted to less than $300 \mathrm{mgday}^{-1}$ is advised.

- Ratio of linoleic ( $n-6$ series) to $\alpha$-linolenic acids ( $n-3$ series) should be between 5:1 and 10:1.

FAO - Food and Agriculture Organization; WHO - World Health Organization; EFA - essential fatty acids.

Source: Joint FAO/WHO Expert Consultation on Fats and oils in human nutrition ${ }^{3}$.

under consideration by the current consultation provide no basis to suggest modifications. A potential additional recommendation that people wishing to lose weight should restrict their fat intake to around 20\% energy would go against the general practice of targeting recommendations towards the healthy population (as opposed to those with therapeutic needs), and would be widely challenged on theoretical grounds. It would, however, be helpful for the new report to give much clearer guidance concerning dietary fat, energy density and the aetiology of obesity.

\section{Discussion of new considerations since the FAO/WHO/UNU 1985 report}

Many of the basic physiological considerations concerning the absorption, digestion and utilisation of the energy-yielding macronutrients have not changed since the 1985 report and do not need to be reviewed again. The only areas in which knowledge does require updating in relation to novel foods are being addressed by Livesey's background paper which formed the basis for a FAO workshop report ${ }^{2}$. The FAO/WHO consultations on carbohydrates ${ }^{4}$ and fats and oils ${ }^{3}$ each provide comprehensive coverage of the metabolism of carbohydrates and fats, and can be referred to in the new report.

The following is a summary of areas in which there have been changes in the global position with respect to intakes or advances in knowledge since the 1985 report. For reasons provided in the introduction the emphasis is placed on fats and carbohydrates.

\section{Global trends in carbohydrate and fat consumption}

Table 3 summarises the major trends in global carbohydrate intakes between 1964 and 1994. According to these food balance data there has been almost a $50 \%$ increase in carbohydrate availability in developing countries but nonetheless a decrease in the percentage of energy that it provides (from $74 \% \mathrm{E}$ to $68 \% \mathrm{E}$ ). In developed countries there has been a decrease in both the absolute carbohydrate intakes and in its contribution to dietary energy (from $59 \% \mathrm{E}$ to $50 \% \mathrm{E}$ ). Details of the composition of these changes in terms of the actual food sources of the carbohydrates can be found in the 1996 consultation report ${ }^{4}$.

Similar trends for dietary fat are shown in Table 4. The key feature is the large increase in availability of fats and oils worldwide. Fat consumption in many areas of the developing world has shown a large percentage increase $^{19}$ especially in Asia where intakes were formerly viewed as being well below desirable levels of intake and were associated with a high prevalence of chronic energy deficiency $(\mathrm{CED})^{20}$. Table 4 shows that, on average, most regions now have access to dietary fat at a level above the FAO/WHO prescribed minimum desirable level of 15\% energy. However, there remain some countries which are below this figure and the population distribution of fat intakes within the poorer countries will clearly include many people whose intakes remain below the desirable 15\% energy target. This level should be restated in the energy report and endorsed as a target above which all individuals should be raised. In the developed world, average fat consumption is above the recommended target of $<35 \%$ energy and recommendations should continue to urge a further reduction especially with regard to controlling obesity.

Table 3 Global trends in dietary carbohydrate availability

\begin{tabular}{lccccc}
\hline & \multicolumn{2}{c}{1964} & & \multicolumn{2}{c}{1994} \\
\cline { 2 - 3 } \cline { 5 - 6 } & $\mathrm{kcal} \mathrm{cap}^{-1}$ per day & \% energy & & $\mathrm{kcal} \mathrm{cap}^{-1}$ per day & \% energy \\
\hline Developing countries & 1500 & 73.8 & & 1751 & 68.1 \\
Developed countries & 1785 & 58.7 & & 1598 & 49.8 \\
World average & 1555 & 66.3 & & 1717 & 63.2 \\
\hline
\end{tabular}

FAO - Food and Agriculture Organization; WHO - World Health Organization.

Source: Joint FAO/WHO Expert Consultation on Carbohydrates in human nutrition ${ }^{4}$. 
Table 4 Global trends in dietary fat availability

\begin{tabular}{lcccccc}
\hline & \multicolumn{2}{c}{1961} & & \multicolumn{2}{c}{1990} \\
\cline { 2 - 3 } \cline { 5 - 6 } & g cap $^{-1}$ per day & \% energy & & g cap $^{-1}$ & per day & \% energy \\
\hline Developing countries & 28 & 13 & & 50 & 18 \\
$\quad$ Africa & 38 & 16 & & 43 & 18 \\
Far East & 22 & 11 & & 45 & 16 \\
Near East & 46 & 19 & & 72 & 22 \\
Latin America & 51 & 20 & & 75 & 25 \\
Developed countries & 69 & 20 & & 107 & 28 \\
$\quad$ Former USSR & 125 & 36 & & 138 & 36 \\
Oceania & 104 & 32 & & 143 & 37 \\
Europe & 124 & 37 & & 151 & 37 \\
North America & & & & & & \\
\hline
\end{tabular}

FAO - Food and Agriculture Organization; WHO - World Health Organization; USSR - Union of Soviet Socialist Republics.

Source: FAO/WHO Joint Expert Consultation on Fats and oils in human nutrition ${ }^{3}$.

\section{Macronutrient interactions: the oxidative bierarchy}

Prentice and colleagues have developed a simple conceptual model (termed 'The Oxidative Hierarchy') which aids in understanding how the body regulates macronutrient balance on any given mixture of fuels consumed $^{7}$. This describes how differences in the body's storage capacity for the different macronutrients have driven the evolution of a hierarchy that governs their priority in fuel selection. Alcohol is at the top of the hierarchy since the storage capacity is zero. When alcohol is consumed it can only be detoxified through oxidation and it can be readily demonstrated that the presence of alcohol suppresses the oxidation of the other three macronutrients ${ }^{7,13,21}$. Carbohydrate and protein (both of which have very limited storage capacities) come next on the hierarchy and both will suppress the oxidation of fat. It has been demonstrated that, in the absence of alcohol, it is alterations in carbohydrate intake which drive the changes in fuel selection ${ }^{22,23}$. This is because the body's carbohydrate stores (primarily in the form of glycogen) are small and thus generate an obligate need for oxidation to match supply in an 'auto-regulatory' manner. Fat comes at the base of the hierarchy. There is an almost unlimited capacity for fat storage, and both body fat and dietary fat exert very little feedback control on levels of fat oxidation $^{24}$

\section{Flexibility of fuel selection to match diet: capacity and limitations}

There has been considerable advance in our understanding of the extent to which the body can adapt its fuel selection in order to match its rate of utilisation of different fuels to the amount provided in the diet. Again this knowledge has derived from detailed manipulative studies using whole-body indirect calorimetry (see above) ${ }^{25-27}$. Figure 1 provides an example showing how alterations in the diet composition from $7 \%$ to $79 \%$ energy from carbohydrate, with reciprocal changes in fat (while protein was held constant at 14\%) cause a major shift in the oxidation of fuels ${ }^{25}$. There is a slight delay in generation of the signal that stimulates these adaptations (assumed to originate in glycogen stores) or in the induction of some of the enzyme systems necessary to accommodate such large fluctuations in diet composition. This is indicated by the fact that the oxidation rates on the second day in Fig. 1 more closely match the diet composition than the rates on the first day. Others have shown that it may take 3-4 days to achieve the full extent of adaptation ${ }^{24,28,29}$. Experiments such as these have now been widely performed in a variety of conditions of energy balance, overfeeding and underfeeding, and all confirm the basic concept that there is an impressive level of plasticity within metabolic fuel selection that allows people to cope on diets of widely varying composition in terms of the fat/carbohydrate ratio.

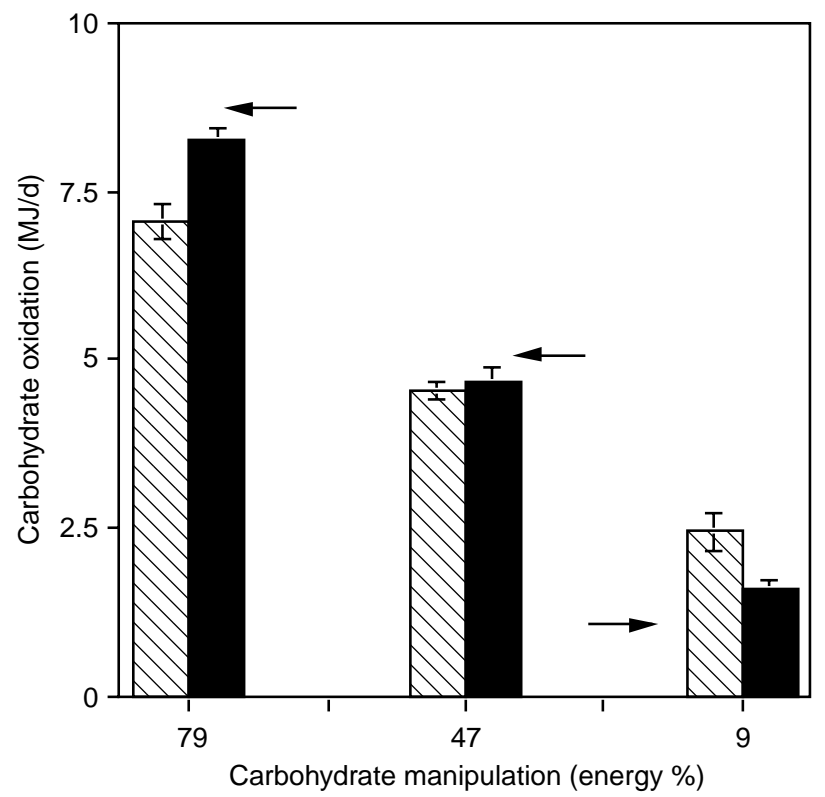

Fig. 1 Flexibility of metabolic fuel selection to match dietary fuel supply; Data show intakes (arrows) and oxidation rates (columns) of carbohydrate on Day 1 (hatched bar) and Day 2 (solid bar) of dietary manipulation. $n=$ six subjects studied by continuous whole-body calorimetry. Redrawn using data from Shetty et al. ${ }^{25}$ 
This leads to two questions of relevance for the current consultation: (1) are there any adverse consequences associated with fuelling the body on a range of different fat: carbohydrate mixtures; and (2) what is the full range over which this can occur over extended time periods?

The answer to the first question is somewhat unknown though, with one exception, there is no a priori evidence to suggest that it should be a problem. The single exception relates to clinical states of respiratory insufficiency where the high respiratory exchange ratio (i.e. high ratio of $\mathrm{CO}_{2}$ production to $\mathrm{O}_{2}$ consumption) associated with high carbohydrate diets could exacerbate metabolic acidosis.

The answer to the second question is, in practice, only important at very high levels of carbohydrate intake since there are no known populations that consume diets that are so low in carbohydrate or high in fat as to approach the levels shown in Fig. 1. Thus, concentrating on the highcarbohydrate/low-fat scenario we see from Fig. 1 that even in subjects not habituated to low-fat intakes it appears possible to adjust fuel selection to accommodate a diet at least as low as 10\% energy from fat. Data from the Far East (e.g. Vietnam) have indicated that some populations have been existing on fat intakes as low as $6-7 \%$ energy $^{3}$. At such low intakes of fat it may be necessary for them to synthesise some fat de novo from carbohydrate; a biochemical process which normally occurs at very low flux and which carries the disadvantage of being metabolically wasteful of energy ${ }^{30,31}$. Such populations are generally extremely lean and may be surviving below their physiological optimum. This was the view of the FAO/WHO consultation on fats and oils which urged measures to raise all populations above 15\% energy from fat. As indicated above most populations have now moved above this figure and those that have not yet attained it are probably well on the way to doing so. Therefore, at least for non-reproducing adults, there seems little likelihood that fat intakes will be so low as to exceed the limits of metabolic adaptation. The advice on minimum fat $\% \mathrm{E}$ for reproductive women and for children proposed in the Joint FAO/WHO Consultation on Fats and oils appears sound and could be reiterated in the present report.

\section{Macronutrients and diet-induced thermogenesis}

The older literature on the topic of diet-induced thermogenesis (DIT) induced by the different macronutrients tended to emphasise the differences observed when subjects were studied acutely in the period following ingestion of each macronutrient in its pure form ${ }^{21,23,27}$. They indicated quite large differences between the so-called 'specific dynamic action' of the macronutrients with protein having the highest level and fat the lowest ${ }^{31}$. Such experiments bear little resemblance to the real life condition when diets contain a varied mixture of energy sources. More recent experiments, conducted with great accuracy in whole-body calorimeters, have demonstrated that there is no detectable difference in thermogenesis over a 24-hour period between diets ranging in fat/carbohydrate ratio as widely as can be reasonably constructed using mixed meals (i.e. between $7 \%$ and $79 \%$ energy from fat with reciprocal changes in carbohydrate) ${ }^{25}$. These studies were conducted at 'normal' levels of protein intake (14-16\% energy). They have not yet been repeated with very high protein intakes, but such diets will presumably not be endorsed by the consultation so this gap in knowledge is of little significance. Similar studies with whole-body calorimetry have shown that the diet-induced thermogenesis associated with alcohol oxidation is rather similar to carbohydrate $^{10}$.

It is concluded that within mixed diets the impact of different macronutrients on DIT can effectively be ignored in relation to energy requirements.

\section{The respiratory quotient (RQ): food quotient (FQ) concept}

In the 1980s J-P Flatt developed the RQ/FQ concept that is pertinent to the current discussion and requires explanation $^{32}$. The RQ is a measure of the proportion of carbon dioxide produced compared to oxygen consumed by the body. It is altered by the composition of the fuel mix being burnt, especially the ratio of fat/carbohydrate. The FQ is an analogous figure but is derived as the theoretical ratio of the gases assuming complete oxidation of the food.

Flatt has pointed out that for an organism to be in energy balance over a long period of time RQ must equal $\mathrm{FQ}^{32}$. He further pointed out that, because carbohydrate (glycogen) stores are small relative to fat stores the fuel selection mechanisms have evolved to be dominated by carbohydrate supply. It was this concept that stimulated the development of the oxidative hierarchy described above. Flatt further reasoned that if a person's habitual diet composition were altered then their body composition would need to change in order to rebalance the FQ/RQ equation $^{32,33}$. He argued, for example, that if a person started consuming a high-fat diet (low FQ) then their body fat would need to increase until the greater fat mass stimulated a greater fat oxidation in order to reduce the RQ and bring it back into line with FQ.

This theory has gained considerable currency and may create significant confusion during the consultation. We have argued that, although many aspects of Flatt's theory have been extremely useful, the proposal that body composition must change to rebalance RQ to FQ is not supported by data ${ }^{34}$. Reference to Fig. 1 shows that fuel selection can be modulated over a very wide range even at the same body composition. Although not plotted in terms of RQ these data were derived from RQ and show that RQ alters rapidly to match FQ. In summary, therefore, Flatt's $\mathrm{FQ} / \mathrm{RQ}$ theory need not confuse the consultation by 
suggesting that body composition will automatically and necessarily change in response to a change in the fat: carbohydrate ratio of the diet.

\section{Macronutrient effects on appetite control}

In addition to the possible effects on the energy expenditure side of the energy balance equation, alterations in the macronutrient composition of the diet may influence appetite and hence energy intake. In young children, in malnourished patients, in the elderly and in emergency situations the aim is often to enhance or even maximise energy intake to ensure optimal growth rates or the rehabilitation of the malnourished state. Under such circumstances a high-fat content (and hence a high energy density) is beneficial. Since the current consultation deals with the healthy population we should focus attention on childhood. The FAO fats and oils consultation ${ }^{3}$ emphasised the high-fat content of breast-milk $(>50 \% \mathrm{E})$ and made specific recommendations about the way in which the transition between breast-milk and adult diet should be handled. The current consultation's group on energy needs of infants will also consider this point so there is no need to cover it further here.

In the reverse direction, there is a pressing need to limit the energy intake of most adults in the developed world in order to avoid weight gain and obesity. The extent to which this can be achieved by promoting a low-fat diet has been investigated in depth, but remains controversial. Experimental evidence obtained by covert manipulation of the fat content of diets universally demonstrates that high-fat diets lead to an accidental over-consumption of energy $^{23,35}$. This can occur at extreme levels. For instance, Stubbs demonstrated that provision of a $60 \% \mathrm{E}$ from fat diet induced almost $100 \mathrm{gday}^{-1}$ fat storage in volunteers compared to a $20 \mathrm{~g} \mathrm{day}^{-1}$ fat mobilisation on a matched diet containing only $20 \%$ energy from fat ${ }^{13,36}$. Similar experiments have been repeated under a variety of experimental settings and the result has been regularly replicated $^{37,38}$. The effect appears to be caused by a lack of an energy-sensing feedback mechanism and it can be shown that it is the increased energy density of high-fat diets which causes the over-consumption rather than any specific attributes of fat itself ${ }^{39-42}$ and the same effect can be obtained by increasing the energy density of foods using carbohydrates ${ }^{43}$. This phenomenon of accidental over-eating has been termed 'passive over-consumption' 44 which is a useful phrase since it articulates the fact that people are not generally being gluttonous but are being misled by an inappropriate combination of energy-dense diets and a sedentary lifestyle.

Although the experimental evidence that high-fat or other energy-dense diets lead to fat gain is robust, the epidemiological evidence is much more confused ${ }^{45}$. In general, it can be demonstrated that obesity correlates with the fat content of diets. This correlation can be observed between individuals ${ }^{16,17,46}$. as well as between population sub-groups within countries and between countries $^{3}$. However, the findings are not always straightforward ${ }^{45,47}$. In particular there has been recent controversy over whether low-fat diets are associated with leanness ${ }^{48-51}$. This controversy has been driven by observations in the US that levels of obesity are continuing to escalate when the fat content of the diet has apparently been declining ${ }^{47,51}$. It would be inappropriate to cover this controversy in detail here, except to note that the paradox can almost certainly be resolved by focussing on the issue of energy density. In the US manufacturers have altered the 'traditional' correlation between fat \% $\mathrm{E}$ and energy density of diets. They have successfully manufactured low-fat products in accordance with guidance provided by nutrition experts, but have substituted other energy-dense ingredients (primarily highly-refined simple carbohydrates) and have thereby maintained or even increased the energy density of foods, thus continuing the population trend towards passive over-consumption.

The current consultation is strongly urged to address this issue of energy density of foods and diets in some detail and with great clarity since it has emerged to be one of the most important considerations with respect to the epidemic of obesity.

\section{Metabolic effects of fats vs. carbohydrates}

Issues pertaining to the possible health-related metabolic effects of diets differing in the ratio of macronutrients are not included within the brief of this paper. However, they are currently forming a central part of the controversy regarding the recommendation of highcarbohydrate/low-fat diets for affluent populations ${ }^{51}$ and will, therefore, need to be considered as part of the consultative process.

\section{Suggested recommendations}

The recommendations arising from this paper are extremely simple as follows:

1. Adopt and restate the recommendations arising from the FAO/WHO consultations on fats and oils ${ }^{3}$ and on carbohydrates $^{4}$ in terms of advice in relation to macronutrients as sources of food energy.

2. Acknowledge that the epidemic of obesity represents the greatest new development since the 1985 report $^{1}$ and devote a considerable amount of attention to this issue in the new report.

3. Provide background information and education concerning the importance of the energy density of diets in maintaining healthy body weight.

4. Address the issue of novel food formulations and the effects that these may have on physiological mechanisms of weight regulation (see also background paper by Livesey ${ }^{2}$ ). 
5. In all other respects acknowledge that physiological mechanisms are well designed to adapt metabolic fuel selection to match the macronutrient composition of the diet over a very wide range. Changes in global food supply are making the circumstances over which this adaptation cannot cope (i.e. very low-fat intakes) increasingly rare.

\section{Areas for further research}

Our understanding of the interactions between the energy-yielding macronutrients at the metabolic level is now sufficiently advanced to cover our needs in terms of energy and protein recommendations. However, understanding of the interplay between cognitive and metabolic effects is still at a very rudimentary stage, and is of critical importance in relation to obesity. For instance, dietary manipulation of the fat:carbohydrate ratio (and hence energy density) has very predictable effects on energy balance when the manipulations are made covertly (see above). When made overtly (i.e. when subjects are informed that they are consuming high-fat or low-fat foods) the effects can be completely different ${ }^{52}$. Similarly, when experiments are conducted across foods with similar ratings of palatability the results are predictable, but we have a relatively poor understanding of the effects of fats and sugars on palatability in different subjects. Drewnowski has shown that obese women tend to favour fat-sweet combinations and obese men tend to favour fat-savoury combinations ${ }^{53}$, but there is little further refinement of this knowledge.

There is also an urgent need for more research on the potential effects on human weight regulation of modern food processing techniques which can manipulate the traditional 'learnt' linkage between macronutrients and energy intake ${ }^{54}$. These relationships form the basis of most people's cognate control of food intake and their disruption is likely to impair the partnership between cognitive and metabolic controls of food intake.

\section{Recommendations for priority areas of future research}

1. The interplay between innate and cognitive responses to foods of varying macronutrient content and palatability.

2. Further research on the influence of energy-density of foods on the maintenance of healthy body weight. Included in this should be studies into the effect of energy density on the palatability/desirability of foods.

3. Further research on the weight-controlling and other metabolic effects of diets differing in macronutrient proportions and in energy density.
4. Further research on the impact in terms of body weight regulation of novel food manufacturing processes that can disconnect the usual relationship between macronutrient composition of foods and their energy density.

\section{References}

$1 \mathrm{FAO} / \mathrm{WHO} / \mathrm{UNU}$. Energy and Protein Requirements. Geneva: World Health Organization, 1985.

2 FAO. Food Energy - Methods of Analysis and Conversion Factors. Rome: Food and Agriculture Organization, 2002.

3 FAO/WHO. Fats and Oils in Human Nutrition. Report of a Joint Expert Consultation. Rome: Food and Agriculture Organization, 1994.

4 FAO/WHO. Carbohydrates in Human Nutrition. Report of a Joint Expert Consultation. Rome: Food and Agriculture Organization, 1996.

5 Suter PM, Schutz Y, Jequier E. The effect of ethanol on fat storage in healthy subjects. New England Journal of Medicine 1992; 326: 983-7.

6 Sonko BJ, Prentice AM, Murgatroyd PR, Goldberg GR, van der Ven MLH, Coward WA. Effect of alcohol on post-meal fat storage. American Journal of Clinical Nutrition 1994; 59: 619-25.

7 Prentice AM. Alcohol and obesity. International Journal of Obesity 1995; 19: S44-50.

8 Lands WEM, Zakhari S. The case of the missing calories. American Journal of Clinical Nutrition 1987; 45: 47-8.

9 Leiber CS. Perspectives: do alcohol calories count? American Journal of Clinical Nutrition 1991; 54: 976-82.

10 Westerterp KR, Prentice AM, Jequier E. Alcohol and body weight. In: Macdonald I, ed. Health Issues Related to Alcohol Consumption. Oxford: Blackwell Science, 1999, 103-23.

11 Rolland-Cachera MF, Deheeger M, Akrout M, Bellisle F. Influence of macronutrients on adiposity development: a follow-up study of nutrition and growth from 10 months to 8 years of age. International Journal of Obesity 1995; 19: $573-8$.

12 Dorosty AR, Emmett PM, Cowin SD, Reilly JJ. Factors associated with early adiposity rebound. ALSPAC Study Team. Pediatrics 2000; 105: 1115-8.

13 Stubbs RJ. Macronutrient effects on appetite. International Journal of Obesity 1995; 19(Suppl. 5): S11-9.

14 Skov A, Toubro S, Ronn B, Astrup A. The effect of a low-fat, high-protein vs, a low-fat, high carbohydrate diet on cardiovascular risk factors in obese subjects. International Journal of Obesity 1996; 20: 47.

15 Skov A, Toubro S, Ronn B, Holm L, Astrup A. Randomised trial on protein vs carbohydrate in ad libitum fat-reduced diet for treatment of obesity. International Journal of Obesity 1999; 23: 528-36.

16 Hill JO, Prentice AM. Sugar and body weight regulation. American Journal of Clinical Nutrition 1995; 62: 264S-74S.

17 Bolton-Smith C, Woodward M. Dietary composition and fat to sugar ratios in relation to obesity. International Journal of Obesity 1994; 18: 820-8.

18 Ludwig DS, Peterson KE, Gortmaker SL. Relation between consumption of sugar-sweetened drinks and childhood obesity: a prospective observational analysis. Lancet 2001; 17: $505-8$.

19 Drewnowski A, Popkin B. The nutrition transition: New trends in global diet. Nutrition Review 1997; 55: 31-43.

20 Ferro-Luzzi A, Sette S, Franklin M, James WP. A simplified approach to assessing adult chronic energy deficiency. European Journal of Clinical Nutrition 1992; 46: 173-86.

21 Prentice AM. Are all calories equal? In: Cottrell R, ed. Weight 
Control: The Current Perspective. London: Chapman \& Hall, 1995, 8-33.

22 McNeill G, Morrison DC, Davidson L, Smith JS. The effect of changes in dietary carbohydrate $\mathrm{v}$. fat intake on 24-h energy expenditure and nutrient oxidation in post-menopausal women. Proceedings of the Nutrition Society 1992; 51: 91A.

23 Prentice AM. Manipulation of dietary fat and energy density: effect on substrate flux and food intake. American Journal of Clinical Nutrition 1998; 67(Suppl.): 535S-41S.

24 Schutz Y, Flatt JP, Jequier E. Failure of dietary fat intake to promote fat oxidation: a factor favouring the development of obesity. American Journal of Clinical Nutrition 1989; 50: 307-14.

25 Shetty PS, Prentice AM, Goldberg GR, Murgatroyd PR, McKenna APM, Stubbs RJ, Volschenk PA. Alterations in fuel selection and voluntary food intake in response to isoenergetic manipulation of glycogen stores in humans. American Journal of Clinical Nutrition 1994; 60: 534-43.

26 Stubbs RJ, Murgatoyd PR, Goldberg GR, Prentice AM. Carbohydrate balance and the regulation of day-to-day food intake in humans. American Journal of Clinical Nutrition 1993; 57: 897-903.

27 Thomas CD, Peters JC, Reed GW, Abumrad NN, Sun M, Hill JO. Nutrient balance and energy expenditure during ad libitum feeding of high-fat and high-carbohydrate diets in humans. American Journal of Clinical Nutrition 1992; 55 : 934-42.

28 Jebb SA, Prentice AM, Goldberg GR, Murgatroyd PR, Black $\mathrm{AE}$, Coward WA. Changes in macronutrient balance during over- and under-nutrition assessed by 12-d continuous whole-body calorimetry. American Journal of Clinical Nutrition 1996; 64: 259-66.

29 Schutz Y, Acheson KJ, Jequier E. Twenty-four hour energy expenditure and thermogenesis: response to progressive carbohydrate overfeeding in man. International Journal of Obesity 1984; 9: 111-4.

30 Hellerstein MK, Christiansen M, Kaempler S, Kletke C, Wu K, Reid JS, Mulligan K, Hellerstein NS, Shackleton CH. Measurement of de novo hepatic lipogensis in humans using stable isotopes. Journal of Clinical Investigation 1991; 87: $1841-52$.

31 Blaxter K. Energy Metabolism in Animals and Man. Cambridge: Cambridge University Press, 1989

32 Flatt J-P. The difference in storage capacities for carbohydrate and for fat and its implications for the regulation of body weight. Annals of the New York Academy of Sciences 1987; 499: 104-23.

33 Flatt J-P. Importance of nutrient balance in body weight regulation. Diabetes 1988; 4: 571-81.

34 Prentice AM. Substrate balance and dietary intake: clinical relevance of the glycogenostatic theory. In: Guy-Grand B, Ailhaud G, eds. Progress in Obesity Research 8. London: John Wiley, 1999, 453-8.

35 Blundell JE, MacDiarmid JI. Fat as a risk factor for overconsumption: satiation, satiety and patterns of eating. Journal of American Dietetic Association 1997; 97: S63-9.

36 Stubbs RJ, Harbron CG, Murgatroyd PR, Prentice AM. Covert manipulation of dietary fat and energy density: effect on substrate flux and food intake in men eating ad libitum. American Journal of Clinical Nutrition 1995; 62: 316-29.

37 Kendall A, Levitsky DA, Strupp BJ, Lissner L. Weight-loss on a low fat diet: consequence of the imprecision of the control of food intake in humans. American Journal of Clinical Nutrition 1991; 53: 1124-9.

38 Lissner L, Levitsky DA, Strupp BJ, Kalkwarf HJ, Roe DA. Dietary fat and regulation of energy intake in human subjects. American Journal of Clinical Nutrition 1987; 46: $886-92$.

39 Stubbs RJ, Harbron CG, Prentice AM. Covert manipulation of the dietary fat to carbohydrate ratio of isoenergentically dense diets: effect on food intake in feed men ad libitum. International Journal of Obesity 1996; 20: 651-60.

40 van Stratum P, Lussenburg RN, van Wezel LA, Vergroesen AJ, Cremer HD. The effect of dietary carbohydrate: fat ratio on energy intake by adult women. American Journal of Clinical Nutrition 1978; 31: 206-12.

41 Poppitt SD, Prentice AM. Energy density and its role in the control of food intake: Evidence from metabolic and community studies. Appetite 1996; 26: 153-74.

42 Prentice AM, Poppitt SD. Importance of energy density and macronutrients in the regulation of energy intake. International Journal of Obesity 1996; 20(Suppl. 2): S18-23.

43 Stubbs RJ, Johnstone AM, O'Reilly LM, Barton K, Reid C. The effect of covertly manipulating the energy density of mixed diets on ad libitum food intake in 'pseudo free-living' humans. International Journal of Obesity 1998; 22: 980-7.

44 Blundell J, Burley V, Cotton J, Delargy H, Green S, Greenough A, King N, Lawton C. The fat paradox: fatinduced satiety signals but overconsumption on high fat foods. International Journal of Obesity 1995; 19: 832-5.

45 Lissner L, Heitmann BL. Dietary fat and obesity: evidence from epidemiology. European Journal of Clinical Nutrition 1995; 49: 79-90.

46 Dreon DM, Frey-Hewitt R, Ellsworth N, Williams PT, Terry RB, Wood PD. Dietary fat: carbohydrate ratio and obesity in middle-aged men. American Journal of Clinical Nutrition 1988; 47: 995-1000.

47 Heini AF, Weinsier RL. Divergent trends in obesity and fat intake patterns: the American paradox. American Journal of Medicine 1997; 102: 259-64.

48 Astrup A. The American paradox: the role of energy-dense fat-reduced food in increasing prevalence of obesity. Current Opinion in Clinical Nutrition and Metabolic Care 1998; 1: 573-7

49 Astrup A, Grunwald GK, Melanson EL, Saris WH, Hill JO. The role of low-fat diets in body weight control: a meta-analysis of ad libitum dietary intervention studies. International Journal of Obesity 2000; 24: 1545-52.

50 Bray GA, Popkin BA. Dietary fat intake does affect obesity. American Journal of Clinical Nutrition 1998; 68: 1157-73.

51 Katan MB, Grundy SM, Willett WC. Should low-fat, highcarbohydrate diet be recommended for everyone? Beyond low-fat diets. New England Journal of Medicine 1997; 337 : 563-6.

52 Cox D, Mela DJ. Determination of energy density of freely selected diets: methodological issues and implications. International Journal of Obesity 2000; 24: 49-54.

53 Drewnowski A, Holden-Wiltse J. Taste responses and food preferences in obese women: effects of weight cycling. International Journal of Obesity 1992; 16: 639-72.

54 Mela DJ. Fat and sugar substitutes: implications for dietary intake and energy balance. Proceedings of the Nutrition Society 1997; 56: 827-40. 